\title{
O diagnóstico de TDAH: implicaçõ̃es na aprendizagem escolar da criança
}

\author{
Rosina Forteski \\ Ricardo Michalak ${ }^{* *}$ \\ Maira Maria da Costa ${ }^{* * *}$ \\ Fabiane Pufal ${ }^{* * *}$ \\ Tánia Mara Nüssner ${ }^{* * * * *}$
}

Resumo: O Transtorno de Déficit de Atenção e Hiperatividade (TDAH) inscreve-se no conjunto das problemáticas identificadas no ambiente escolar na contemporaneidade. Fator sabidamente promotor de sofrimento, conflitos e defasagens em diversos contextos, o TDAH tende a se apresentar como uma condição contribuinte para o fracasso escolar. Para a construção deste artigo, buscou-se investigar as relações entre o diagnóstico de TDAH e suas implicações na aprendizagem escolar. Conclui-se, com este artigo,o que o diagnóstico pode ser utilizado como justificativa para o fracasso escolar por um viés que culpabiliza a criança e isenta os demais responsáveis. Neste sentido, uma preocupação consistente diz respeito à capacitação dos profissionais envolvidos no tratamento da criança e nas demais pessoas responsáveis pelo seu cuidado, pois o uso tendencioso e irresponsável do diagnóstico e dos meios de tratamento pode contribuir para a aniquilação das expressões idiossincráticas da criança.

\footnotetext{
* Graduanda do Curso de Psicologia da Faculdade Metropolitana de Guaramirim. E-mail: sinateski@fameg.edu.br.

* Graduando do Curso de Psicologia da Faculdade Metropolitana de Guaramirim. E-mail: ricaro@gmail.com.

** Graduanda do Curso de Psicologia da Faculdade Metropolitana de Guaramirim. E-mail: mairadacosta@hotmail.com.

*** Graduanda do Curso de Psicologia da Faculdade Metropolitana de Guaramirim. E-mail: fabifupal@hotmail.com.

*****Graduanda do Curso de Psicologia da Faculdade Metropolitana de Guaramirim. E-mail: tmnusser@fameg.edu.br.
} 
Palavras-chave: TDAH; Psicologia; Fracasso escolar; Diagnóstico; Implicações.

\begin{abstract}
The Disorder of the Deficit of Attention and Hyperactivity (ADHD) is in the group of problems identified in the scholar setting in the contemporaneity. Factor known as a promoter of suffering, conflicts and gaps in different contexts, ADHD to be itself as a contributing condition to school failure. To construct this article was necessary to investigate the relations between the diagnosis of the TDAH and its implications in the scholar learning. In conclusion, the diagnosis can be used as a justification in a way that accuses the kid, taking off the others' responsibility. In this way, a consistent preoccupation is related to the capacitation of the involved professionals in the kids' treatment, and in the other people responsible for their care, because the tendentious and irresponsible use of the diagnosis and of the treatment ways can contribute to the destruction of the kids' idiosyncratic expressions.
\end{abstract}

Keywords: ADHD; Psychology; Scholar unsuccessfulness; Diagnosis; Implications.

\title{
Introdução
}

O Transtorno de Déficit de Atenção e Hiperatividade (TDAH) inscreve-se no conjunto das problemáticas identificadas no ambiente escolar na contemporaneidade. $\mathrm{O}$ que define o TDAH, segundo o sistema classificatório do Manual Diagnóstico e Estatístico de Transtornos Mentais - DSM (2002) é a existência de um padrão persistente de desatenção que pode estar associado ou não a manifestações de hiperatividade. A apresentação desses sintomas precisa ocorrer em maior grau do que nos indivíduos de desenvolvimento típico. Os prejuízos advindos dos sintomas 
devem ser identificados em pelo menos dois contextos diferentes e a constatação do comprometimento dos sintomas na vida social, acadêmica e laboral do indivíduo deve se basear em evidências.

De acordo com De Luca e Ciulik (2009), o TDAH atinge entre 3 e $6 \%$ de crianças com faixa etária de 7 a 14 anos. Nessas crianças, comportamentos de desatenção, inquietação e impulsividade são os mais constatados. É típico da criança que apresenta o transtorno não conseguir ficar parada, correr por ambientes de forma descontrolada e injustificada, arranhar-se descontroladamente, apresentar dificuldade de concentração e esquecer tarefas rotineiras. De maneira mais específica, dentre os comportamentos impulsivos mais típicos, pode-se citar a intromissão na conversa dos outros e no andamento das aulas sem motivos aparentes e a dificuldade de aguardar sua vez. Ressalte-se que correr de forma descontrolada e injustificada também pode ser considerado um comportamento impulsivo, além de hiperativo, e levar a criança a se envolver em situaçôes de risco.

A alta incidência do TDAH na atualidade permite uma abertura para algumas considerações relativas ao momento histórico atual. Neste sentido, alguns pontos são levantados por Benedetti e Urt (2008). Os autores consideram ser necessário considerar três fenômenos do contexto contemporâneo para a compreensão do TDAH: o progresso cada vez mais veloz da tecnologia, o despreparo cada vez maior da escola, dos professores e da família para lidar com o avanço e a eficiência dos processos eletrônicos e da comunicação, e, por fim, o fato de vivermos o tempo do descartável.

Dada a relevância do tema, emerge urgentemente o seguinte questionamento: o conhecimento existente acerca do TDAH é acessível para as populações que estão de alguma forma envolvidas com o fenômeno? Segundo Gomes et al. (2007) ainda não há clareza quanto às informações sobre o transtorno no Brasil. Esta observação é válida tanto para a população em geral quanto para os profissionais mais diretamente envolvidos nos processos de diagnóstico e tratamento. Os autores salientam, no entanto, que, dentre a população dos profissionais, os médicos e os 
psicólogos são os que apresentam um nível mais satisfatório de conhecimento do assunto, ainda assim percebem-se contradiçôes e posicionamentos vagos no discurso de ambos. Em função disso, os autores sustentam se fazer necessária e urgente a implantação de programas de capacitação que atinja toda a diversidade dos sujeitos que lidam com TDAH, desde clínicos gerais e pediatras, passando por educadores e psicólogos e se estendendo a pais e demais familiares. Aumentando assim a confiabilidade do diagnóstico e a eficácia do tratamento.

Buscou-se, com este artigo, em um primeiro momento, caracterizar o TDAH, levantando aspectos capazes de elucidar seus desdobramentos. Em um segundo momento, o esforço foi realizado no sentido de investigar as relações entre o diagnóstico de TDAH e suas implicações na aprendizagem escolar, objetivo central deste trabalho.

\section{Método}

Para a execução do presente trabalho, foi realizada uma ampla pesquisa bibliográfica, com a finalidade de investigar as relações entre o diagnóstico de TDAH e suas implicações na aprendizagem escolar. O objetivo de uma pesquisa bibliográfica, segundo Marconi e Lakatos (2003), é aproximar o pesquisador de tudo o que já foi produzido sobre o tema, nos mais diversos formatos que podem estar disponíveis por publicação ou gravação. A pesquisa bibliográfica não se resume, no entanto, à reprodução do que já foi dito por outrem, pois visa a propor uma releitura do tema sob uma nova perspectiva.

O TDAH é um transtorno identificado também em adultos, no entanto esta pesquisa faz referência à população infantil em situação escolar. TDAH foi o tema amplo abordado e as implicações do diagnóstico do transtorno na aprendizagem escolar infantil representam os temas delimitados e norteadores das reflexões e discussões ao longo do texto propostas. 


\section{Resultados e discussão}

Fator sabidamente promotor de sofrimento, conflitos e defasagens em diversos contextos, o TDAH tende a se apresentar como uma condição contribuinte para o fracasso escolar. De acordo com Ritter (2009), a criança com TDAH tem uma maior probabilidade de apresentar problemas de aprendizagem que podem resultar em baixo rendimento acadêmico, repetência, evasão escolar e dificuldades de relacionamento. $\mathrm{O}$ fracasso escolar tem instigado pesquisadores e estudiosos das mais diversas áreas. Atualmente, não somente os profissionais de Pedagogia e Psicopedagogia debruçam-se sob tal problemática que denuncia uma gama multifacetada de insuficiências. Por entender Saúde e Educação enquanto campos retroalimentares que convivem e codependem, em uma relação dialética de contribuições e influências, a Psicologia tem direcionado seus intentos investigativos também para a área educacional, contribuindo de maneira relevante com uma vasta gama de produçôes científicas.

A literatura consultada destaca que trabalhar com crianças que apresentam o TDAH não é uma tarefa fácil e que a compreensão do diagnóstico como o fim de um processo de procura por culpados é comum. Tal atitude, porém, tende a abafar a fragilidade do sistema educacional e a incapacidade dos professores, pais, e demais envolvidos com a aprendizagem da criança frente às demandas e consequências de conviver, cuidar e ensinar uma criança com TDAH. Vislumbra-se, no desvelamento das relações enraizadas no fenômeno, que concepções e posturas pouco plásticas podem promover a marginalização destas crianças, que por sua vez tendem a apresentar um desempenho aquém do esperado. Por outro lado, mostra-se cada vez mais ansiosa a busca por bodes expiatórios que alvitrem paradigmas como o da exclusão dos "desajustados" em favor do sossego e do progresso daqueles que mantém alimentado o padrão vigente de bom aluno. $\mathrm{O}$ vidro é fino, as suposições podem ser precipitadas, ainda assim, 
as possibilidades para a manutenção deste cenário separatista presentes no cotidiano são convidativas.

\section{Caracterização e diagnóstico}

O diagnóstico da criança com TDAH é feito com base na sintomatologia descrita pelo DSM IV ou pelo CID X, tendo ainda como critério base a apresentação dos sintomas relacionados ao transtorno em pelos menos dois ambientes distintos. Mas quem são os alunos com TDAH, ou, que comportamentos emitem para que sejam identificados com TDAH? De Luca e Ciulik (2009) relatam que o aluno que apresenta o transtorno é aquele que tem um histórico de inquietação, desatenção e impulsividade. Exemplificando de maneira mais específica, a criança com TDAH apresenta dificuldades de se manter sentada, é propensa a escalar móveis e dispara em corridas inesperadas entre eles, faz intromissões em conversas alheias e se mantém desatenta em classe. No entanto, Ritter (2009) propõe que, apesar da acusação comum de desatenção, alunos com TDAH prestam atenção a tudo. A deficiência manifesta-se na dificuldade de utilizar a atenção seletivamente, de emitir respostas rápidas e planejar com antecedência. Dessa forma, o relato de profissionais tem demonstrado indícios de defasagens e contradições no reconhecimento do aluno com TDAH, uma vez que comportamentos nomeados como de inquietude ou indisciplinar são comuns a qualquer aluno e podem apenas estar sinalizando as dificuldades do aluno com o sistema escolar proposto em geral (DALLANORA et al., 2007).

A identificação e a avaliação do transtorno têm se apresentado, de certa forma, como um desafio particular. Messina e Tiedemann (2009) indicam três fatores que dificultam a avaliação da criança com TDAH, sendo esses a dificuldade de classificação, de estabelecer critérios de diagnóstico e a inexistência de normas específicas para avaliar aspectos como a atividade motora e o nível 
de atenção/concentração. De modo que é preciso avaliar criteriosamente a suspeita de uma criança com TDAH, principalmente pela falta de divulgação de informações corretas para sociedade e para os principais agentes do sistema educacional (GRAEFF; VAZ, 2008). Nesse sentindo é válido o apontamento de Reis e Camargo (2008) que nos fala da complexidade da problemática que aparece de maneira paradoxal, pois, de um lado, tem-se o uso inadvertido do termo "distúrbio/transtorno" em função de uma tendência da literatura a culpabilizar alguém, enquanto, por outro lado, o fenômeno TDAH permanece desconhecido ou visto com descrença pela sociedade.

Ao considerar-se o acelerado crescimento do número de crianças diagnosticadas com o transtorno, uma genuína preocupação frente à utilização dos diagnósticos se faz pertinente. Para tanto, os autores Landskron e Sperb (2008) alertam para a periculosidade do diagnóstico médico entendido enquanto "sacramento", portanto incontestável e imperativo. Esta noção exagerada de confiabilidade pode trabalhar em deferimento de posturas passivas diante de melhorias que poderiam ser planejadas no ambiente escolar. Assim, permanecem vigentes os métodos convencionais e ortodoxos, sem que ao menos sejam consideradas outras alternativas para mudanças e readaptações em favor da aprendizagem do aluno, que, por sua vez, é tido como doente e incapaz.

Outro fato a ser considerado é o efeito sectarista que a constatação do transtorno pode possibilitar, contribuindo para a construção de uma tipologia rotulante e classificadora que marginaliza a criança que se comporta atipicamente. Benedetti e Urt (2008) confirmam esta situação sugerindo que a falta de informações adequadas sobre o TDAH é um fator que propicia a emergência de estereótipos, pois o aluno rotulado passa a figurar como modelo de comportamentos inadequados. No entanto, as demandas de desempenho acadêmico relacionam-se com aspectos culturais e históricos específicos de cada escola e precisam, portanto, ser consideradas na avaliação de cada situação. 
A identificação de crianças com TDAH tem relevância quando se passa a discriminar o que elas fazem, e sob que condições o fazem. De outra forma, pode significar só mais um processo de classificação com probabilidade de acrescer os prejuízos no seu processo de aprendizagem e desenvolvimento.

A tênue diferenciação entre a criança que apresenta o transtorno TDAH e a criança que apresenta comportamentos incompatíveis com as exigências históricas e sociais entrega a fragilidade e a limitação dos sistemas classificatórios que são parâmetros para o diagnóstico. Nesse sentido, Caliman (2009) lembra que o Consenso Internacional sobre TDAH assume que os sistemas de riscos compostos por comportamentos inadequados são baseados em princípios morais. Nestes sistemas, os indivíduos saudáveis, ou adequados às regras, ditam as normas nas quais os indivíduos doentes, ou incompatíveis à demanda, devem se adequar. Para Benedetti e Urt (2008), somente uma análise cuidadosa das dimensões socioculturais e psicológicas do indivíduo proporcionaria uma leitura honesta de suas condições.

Cumpre abrir espaço aqui para uma breve explanação acerca dos prejuízos psicológicos e emocionais da criança diagnosticada com TDAH, que advém dos relacionamentos que ela empreende nos seus diversos ambientes. Ribeiro (2008) exemplifica esta possibilidade falando da rejeição entre os colegas da escola que trabalha em detrimento da autoestima da criança com TDAH. A escola é uma arena fértil para o desenvolvimento de sentimentos de pertencimento a um grupo social e é neste espaço que os comportamentos de impulsividade e hiperatividade associados à inabilidade de aceitar regras dificultam a aquisição de habilidades sociais pela criança. Como consequência final da soma das dificuldades próprias da criança com os efeitos colaterais da hostilidade, da rejeição e da discriminação surge o isolamento social.

No que tange aos paradoxos cultivados pela sociedade atual, importantes considerações são feitas por Eidt e Tuleski (2010, p. 22): 
Se compreendemos que o desenvolvimento do capitalismo e, mais recentemente, que a reorganização desse modo de produção vêm gerando uma sociedade impaciente e imediatista, o que implica uma reestruturação de ações, comportamentos, afetos e sentimentos, e se concebemos que nos indivíduos estão consubstanciadas as características humanas comuns a cada época histórica, como mostra a psicologia histórico-cultural, entende-se que os transtornos mentais e de comportamento, entre eles o TDAH, precisam ser analisados em suas múltiplas determinações, uma vez que expressam as contradições da sociedade atual.

As investigações a respeito do TDAH, suas características e implicações na aprendizagem da criança demanda que sejam transcendidas as variáveis biológicas. Questões políticas, éticas, econômicas e morais permeiam o sistema de ensino. Relevantes desdobramentos podem ser realizados se considerarmos o fato de que o surgimento do diagnóstico do TDAH é concomitante com uma época econômica na qual o indivíduo bem sucedido, produtivo e feliz é aquele que apresenta características de autogestão, atenção direcionada, consciência, racionalidade e prudência (CALIMAN, 2009). Estar em desacordo com este idealismo pode significar uma postura não desejada por um sistema educacional que prepara indivíduos para o desenvolvimento e para a manutenção da hegemonia capitalista.

\section{Tratamento e intervenção}

O diagnóstico da criança com TDAH ocorre, muitas vezes, enquanto resultado final, em vez de apresentar-se como ponto de partida para um planejamento diferenciado que permita condições satisfatórias de aprendizagem para a criança. Conforme questão levantada por Benedetti e Urt (2008), vem ocorrendo frequentemente o encaminhamento de alunos com TDAH para tratamento clínico, o que pode indicar uma visão unifatorial que deposita no indivíduo as possibilidades de culpa e proporciona a expiação dos demais envolvidos na questão. Em 
uma avaliação com essas características, as questões socioculturais são desprezadas.

A concepção docente a respeito do uso medicamentoso, no caso do TDAH representado majoritariamente pela Ritalina, tem apresentado os dois lados do tratamento medicamentoso. Em pesquisa realizada por Dallanora et al. (2007), os autores constataram, no relato da maioria dos professores entrevistados, uma concordância quanto à eficácia do uso da Ritalina nos alunos detectados com TDAH. Considerando como critérios de avaliação, no entanto, fatores como adaptação às normas, regras e ao aumento de atenção. Alguns entrevistados, porém, apresentaram argumentos críticos em relação ao uso medicamentoso, relatando que o resultado da medida é uma criança dopada em sala que, em função disso, tem seus processos de aprendizagem prejudicados. Já as psicoterapias, foram descritas como alternativas mais eficientes e menos danosas.

Para Landskron e Sperb (2008), o uso crescente de medicamentos para tais fins sugere a busca velada pela adequação normativa da criança. Para os autores, este procedimento pode ser pernicioso, uma vez que descarta análises posteriores e criteriosas das variáveis individuais, sociais e institucionais envolvidas. Paralelamente, Benedetti e Urt (2008) denunciam as conveniências advindas de um encaminhamento clínico, relatando ser esta uma ação reducionista que permite à escola e à família se isentarem de suas responsabilidades. No entanto, Landskron e Sperb (2008), em estudo realizado com professoras, constataram que aquelas que não ficam à espera da medicação e usam a experiência e o conhecimento adquirido para acolher e fortalecer a autoestima do aluno acabam conquistando o afeto e a confiança da criança. Essas professoras optaram pelo uso de atividades gratificantes, pela oferta de atenção personalizada e por evitar puniçôes excessivas. Afinal, se criança com TDAH apresenta demandas particulares, ela precisa que sejam desenvolvidas atividades que a instigue a aprender e que facilite a sua aprendizagem. 
Fato é que posicionamentos opostos se levantam quando o assunto em pauta é a normatização da criança. De um lado, diferentes sistemas têm buscado meios de sossegar e disciplinar crianças entendidas como atípicas, esperando assim potencializar e direcionar a sua funcionalidade nas tarefas acadêmicas. Porém, de outro, aventa-se uma preocupação com os aspectos éticos envolvidos no empreendimento de ceifar as diversidades dos indivíduos, conforme pondera Ribeiro (2008, p. 23):

[...] simplesmente "normalizar" sem levar em conta as formas ou os meios seria dar-lhes a chance de ser iguais, mas talvez roubar-lhes a chance de ser diferentes, de desenvolver suas próprias habilidades incomuns e trazer de dentro de si o novo, que sempre encantou o mundo e empurrou o conhecimento em direçốes antes não imaginadas.

A opção medicamentosa possibilita também outros desdobramentos, vinculados a uma crítica ao modelo de atenção predominantemente biomédico, conforme sugere Eidt e Tuleski (2010, p. 4):

O uso cada vez mais disseminado de medicamentos em crianças consideradas portadoras de TDAH, nesses últimos anos, sugere a prevalência dessa visão idealista, naturalizante e biologizante acerca da constituição do psiquismo humano. Esse tipo de tratamento é dirigido às manifestações individuais de supostas disfunções do cérebro, separadas da realidade objetiva e do contexto em que se desenvolvem.

No mesmo caminho, Garrido (2007) edifica uma contundente crítica contra a mecanização dos procedimentos de avaliação e tratamento vigentes na atualidade, argumenta o autor que o seguimento cego e descontextualizado, tanto dos manuais de Psicologia quanto dos pressupostos hegemônicos da Medicina avultaram ao longo dos anos efeitos calamitosos nos terrenos da Educação. O fenômeno contemporâneo da medicalização em massa de crianças pode esconder uma ânsia pelo silêncio dos conflitos e nesta situação lhes é negada uma vivência autêntica de suas subjetividades. 
A utilização do diagnóstico de TDAH como justificativa para o fracasso escolar tem se mostrado frequente e, segundo Graeff e Vaz (2008), essa ocorrência tem aumentado dia a dia. De forma semelhante, Landskon e Sperb (2008) encontraram em seus estudos uma crescente tendência de "patologização" dos problemas de aprendizagem. $\mathrm{O}$ aluno que não desenvolve um repertório de aprendizagem adequado à demanda estatística rapidamente se vê classificado como deficiente ou como portador de uma personalidade problemática. Não raro, estão aí envolvidas respostas emocionais condicionadas, como efeitos colaterais de um histórico de punições e ameaças.

O TDAH, como dantes mencionado, é um transtorno comportamental multideterminado. A forma como o percebemos define, em grande parte, a maneira como dele trataremos. Os determinantes que estabelecem as percepções hegemônicas a respeito do tema, também, por sua vez, nascem de uma derivação múltipla. Neste sentido, Ribeiro (2008) esclarece que a constituição do homem moderno atende às expectativas, necessidades e conveniências de quem estabelece os padrões a serem seguidos e esta relação é possibilitada pelo avanço irrefreável da tecnologia. Em um mundo no qual o nível de satisfação e reconhecimento social é medido pela eficácia e pelo sucesso individual, a tecnologia encontra espaço para manipular interesses e prioridades que criam um novo ideal de homem e trazem consigo outros dilemas éticos. Até mesmo as instituições educadoras aproveitam-se destas ânsias modernas e utilizam o sucesso dos alunos para sua própria propaganda e consequente aumento de lucro. Para finalizar, compõe ainda este cenário o faturamento de bilhões de dólares que as companhias farmacêuticas obtêm com a venda de medicações. 


\section{A atuação do professor}

A perspectiva do professor, que guia sua abordagem em sala, comumente denuncia uma concepção focada apenas nas dificuldades do aluno. De acordo com Dallanora et al. (2007), o professor precisa compreender o educando na totalidade do seu contexto particular, evitando basear-se apenas em uma de suas características. $\mathrm{O}$ rótulo não favorece o conhecimento do professor sobre suas habilidades e muito menos representa subsídios à tarefa do docente de auxiliar a criança em suas dificuldades. $\mathrm{O}$ rótulo tende a reduzir as possibilidades da criança, as habilidades que ela já possui e as que poderia vir a desenvolver, limitando-a a ser referenciada unicamente em função dele. Assim, quando entende-se a criança sob uma ótica exclusiva, corre-se o risco de ela mesma aceitar tal perspectiva como única definição de si mesma, e por fim supervalorizar suas dificuldades em detrimento de suas qualidades e potencialidades.

Práticas que enfatizam as deficiências e, ao mesmo tempo, desconsideram os méritos dos alunos constituem sistemas educacionais coercitivos. Estudos sobre coerção como os realizados por Sidman (1989) denunciam os efeitos colaterais perniciosos das práticas coercitivas escolares. Segundo o autor, crianças expostas somente a modelos coercitivos de aprendizagem tendem a repeti-los se chegarem a exercer a profissão de professor, perpetuando assim um sistema no qual crianças são punidas por não aprenderem e em contraponto crescem menosprezando seus mestres, odiando a escola e esquivando-se dos processos de aprendizagem. Skinner (2000) chama a atenção para a mera alternância histórica das ferramentas de controle coercitivo. Assim, no lugar da palmatória de outrora, hoje em dia, o professor manipula os eventos motivadores disponíveis, utilizando-os como mercadoria de barganha, tornando por fim o processo de ensino aversivo. No atual sistema de ensino, é comum que os alunos trabalhem em função de ameaças e as avaliações identifiquem apenas o conhecimento que o aluno não dispõe. Estas 
condições são desestimulantes para alunos que apresentam um desenvolvimento típico, no entanto, para alunos que apresentam dificuldades de aprendizagem em função do TDAH o prejuízo acadêmico e o sofrimento pessoal aumentam consideravelmente.

Landskron e Sperb (2008) constataram ainda em seus estudos que o relato de professoras descrevendo o trabalho com crianças com TDAH e com suas respectivas famílias envolvia sentimentos de irritação e impaciência, comportamentos de esquiva e fuga e indícios de frustração. O professor se vê desamparado, esperando por uma solução externa, fora de sua competência. Com isso, tem-se o professor como principal agente mais próximo às dificuldades escolares da criança, mas que por fim não tem as informações e as habilidades adequadas e suficientes para auxiliá-la no seu desenvolvimento.

Pais, escola e professores precisam trabalhar juntos para a melhoria das condições de ensino disponibilizadas à criança que apresenta o transtorno. Ajustes e planejamentos personalizados precisam ser efetuados com este objetivo. Conforme relata Ritter (2009), a sala de aula deve ser bem estruturada, com poucos alunos. Também as rotinas diárias consistentes e um ambiente previsível ajudam as crianças a manter o controle sob suas respostas emocionais. Estratégias de ensino que incorporam a atividade física no processo de aprendizagem são importantes e as tarefas propostas não devem ser muito longas e devem ser explicadas passo a passo. $\mathrm{O}$ aluno com TDAH deve receber atendimento individualizado e se sentar na primeira fila, próximo à professora e longe da janela, para que a probabilidade de distração seja menor. Reis e Camargo (2008) acrescentam ainda que o processo de ensino-aprendizagem deve partir de um princípio no qual as ações apresentadas pelo professor forneçam condições para a emissão dos comportamentos-alvo dos discentes. A habilidade de manipulação das condições de ensino pelo educador, de acordo com as exigências e as características dos alunos, conforme Landskron e Sperb (2008), é determinante para a obtenção de resultados satisfatórios. A adequação deve ser sempre estruturada de forma a adaptar as metodologias aos alunos, nunca na direção oposta. 


\section{Considerações finais}

Para a construção deste artigo, buscou-se investigar as relações entre o diagnóstico de TDAH e suas implicações na aprendizagem escolar. Nas reflexôes propostas, o diagnóstico surgiu como um elemento controverso no processo, pois o seu uso pode bem se apresentar como solução final para inquietações de pais, professores e direção escolar, e não como premissa para uma intervenção em favor da criança, realizada por uma equipe multidisciplinar e construída a partir das questôes situacionais por ela enfrentadas.

Percebeu-se também que uma preocupação consistente diz respeito à capacitação dos profissionais envolvidos no tratamento da criança e das demais pessoas responsáveis pelo seu cuidado. Observou-se que as intervençôes e o modo de se relacionar dos professores tendem a se basear apenas em sua experiência, revelando uma atuação intuitiva efetuada por profissionais desamparados e inseguros frente às demandas específicas das crianças com TDAH. Diante destas constatações, sugere-se a construção de protocolos de atendimento que amparem pais e professores, mas que sejam apenas norteadores básicos do cuidado e da atenção, pois as particularidades de cada criança são os fatores a partir dos quais todas as intervençóes devem partir.

A literatura fala-nos dos prejuízos acadêmicos, sociais e psicológicos que surgem como implicaçóes do TDAH para a criança, no entanto, o diagnóstico pode ser utilizado como justificativa para o fracasso escolar por um viés que culpabiliza a criança e isenta os demais responsáveis. O desempenho escolar da criança é prejudicado e nesta situação ela precisa de acolhimento, suporte e reestruturação de suas atividades. Estes são procedimentos que cabem aos pais e professores enquanto tutores de seu bem-estar e agentes potencializadores de suas possibilidades de aprendizagem. Neste sentido, o uso tendencioso e irresponsável do diagnóstico e dos meios de tratamento pode gerar a aniquilação das expressões idiossincráticas da criança. Como bem 
o analisa Garrido (2007), persiste na atualidade a busca pelo refreamento de uma característica fundamental da constituição dos sujeitos: a imprevisibilidade. Esta postura parece ao autor tratar-se de uma fuga do desconhecido e das possibilidades de se surpreender com o outro, este estranho em construção no mundo. Assim, o próprio ato educativo perde seu sentido mais próprio de auxiliar na constituição das vicissitudes do sujeito, em sua relação com o outro.

A escola é uma agência de controle da sociedade e responde, em grande parte, pela sociedade que teremos no futuro. Para Skinner (2000), são as agências de controle às quais o indivíduo está submetido que possibilitam que as classes de comportamentos sejam dicotomizadas em boas (corretas) ou ruins (erradas) e assim ele é incentivado de acordo com esta classificação. A inobservância dessas possibilidades de manipulação social é comum, pois as formas de controle postas em prática pelas mais diversas agências controladoras podem ser tão sutis que fogem à percepção e se misturam às questões culturais. A crise atual do ensino apresenta indícios de que temos ainda muito a trabalhar, para que a democracia se faça presente nos campos da Educação. Conforme Skinner (1972), o ensino deveria se apresentar como o arranjo de melhores contingências para que ocorresse uma aprendizagem eficiente; nesta perspectiva o professor é um facilitador da aprendizagem do aluno. Em contrapartida, a realidade desnuda que persevera em muitas ocasióes um esquema de ação docente em prol da manutenção de uma disciplina unificadora como meio de promover alunos passivos, obedientes e submissos à escola e ao modelo de ordem que eles representam. Um paradigma educacional que objetiva formar alunos com essas características pode estar preparando para a sociedade futuros cidadãos alienados e desinteressados politicamente. 


\section{Referências}

ASSOCIAÇÃO PSIQUIÁTRICA AMERICANA (APA). Manual diagnóstico e estatístico de transtornos mentais. 4. ed. Porto Alegre: Artmed, 2002.

BENEDETTI, Ieda; URT, Sônia da Cunha. Escola, ética e cultura contemporânea: reflexões sobre a constituição do sujeito que "não aprende". Psicologia da Educação, São Paulo, n. 27, p.141-155, jul./dez. 2008.

CALIMAN, Luciana Vieira. A constituição sócio-médica do "fato TDAH”. Psicologia \& Sociedade, Florianópolis, v. 21, n. 1, p. 135-144, jan./abr. 2009.

DALLANORA, Adriana Rossetto et al. A relação da escola com o transtorno de déficit de atenção e hiperatividade nos vales do Rio Pardo e Taquari - RS: um pensamento atual. Psicologia em Pesquisa, Juiz de Fora, v. 1, n. 1, jun. 2007.

DE LUCA, Marcelo Alexandre Siqueira; CIULIK, Fabiane. O professor do ensino fundamental e os alunos em sala de aula: uma distinção entre indisciplina e indícios de TDAH. Futureschool, Curitiba, 2009.

EIDT, Nadia Mara; TULESKI, Silvana Calvo. Transtorno de déficit de atenção/hiperatividade e Psicologia histórico-cultural. Cadernos de Pesquisa, v. 40, n. 139, p. 121-146, jan./abr. 2010.

GARRIDO, Renata. A medicalização do sofrimento psíquico: considerações sobre o discurso psiquiátrico e seus efeitos na Educação. Educação e Pesquisa, São Paulo, v. 33, n. 1, p. 151-161, jan./abr. 2007.

GOMES, Marcelo; et al. Conhecimento sobre o transtorno do déficit de atenção/hiperatividade no Brasil. Jornal Brasileiro de Psiquiatria, v. 56, n. 2, p. 94-101, 2007.

GRAEFF, Rodrigo Linck.; VAZ, Cícero Emidio. Avaliação e diagnóstico do transtorno de déficit de atenção e hiperatividade (TDAH). Psicologia USP, São Paulo, v. 19, n. 3, p. 341-361, jul./set. 2008.

LANDSKRON, Lílian Marx Flor; SPERB, Tania Mara. Narrativas de professoras sobre o TDAH: um estudo de caso coletivo. Associação Brasileira de Psicologia Escolar e Educacional, Campinas, v. 12, n. 1, p. 153-167, jan./jun., 2008. 
MARCONI, Marina de Andrade; LAKATOS, Eva Maria. Fundamentos de metodologia científica. 5 ed. São Paulo: Atlas, 2003.

MESSINA, Lucinete de Freitas; TIEDEMANN, Klaus Bruno. Avaliação da memória de trabalho em crianças com transtorno do déficit de atenção e hiperatividade. Psicologia USP, São Paulo, v. 20, n. 2, p. 209-228, abr./ jun. 2009.

REIS, Maria das Graças Faustino; CAMARGO, Dulce Maria Pompêo de. Práticas escolares e desempenho acadêmico de alunos com TDAH. Associação Brasileira de Psicologia Escolar e Educacional, Campinas, v. 12, n.1, p. 89-100, jan./jun. 2008.

RIBEIRO, Vânia Lúcia de Morais. A família e a criança/adolescente com TDAH: relacionamento social e intrafamiliar. Dissertação (Mestrado em Educação), Universidade Federal de Minas Gerais, Belo Horizonte, 2008.

RITTER, Helena Straceione. Psicopedagogia atuando na reeducação dos pais de crianças com TDAH. Clínica psicopedagogia, São Paulo, jan. 2009.

SIDMAN, Murray. Coerção e suas implicações. São Paulo: Whorkshopsy, 1989.

SKINNER, Burrhus Frederic. Ciência e comportamento humano. São Paulo: Martins Fontes, 2000. Paulo, 1972.

. Tecnologia do ensino. São Paulo: Ed. Universidade de São 